\title{
Emerging evidence on the link between depressive symptoms and bone loss in postmenopausal women
}

This article was published in the following Dove Press journal: International Journal of Women's Health

\author{
Elizabeth Mollard' \\ Laura Bilek ${ }^{2}$ \\ Nancy Waltman' \\ 'College of Nursing, University of \\ Nebraska Medical Center, Lincoln, \\ $\mathrm{NE},{ }^{2}$ College of Allied Health \\ Professionals, University of Nebraska \\ Medical Center, Omaha, NE, USA
}

Correspondence: Elizabeth Mollard College of Nursing-Lincoln Division, University of Nebraska Medical

Center, I 230 O St, STE I3I, Lincoln, NE 68508, USA

Tel +l 4024723665

Fax + I 4024727345

Email elizabeth.mollard@unmc.edu

\begin{abstract}
Osteoporosis and depression are major health problems of crisis proportions in postmenopausal women. Researchers have established a relationship between bone loss and depression, although few studies have focused on postmenopausal women. The purposes of this integrative review were to synthesize and summarize the available literature on: 1) the associations between bone loss and depression in postmenopausal women; and 2) potential variables that impact the associations between bone loss and depression in postmenopausal women. After searching the databases PubMed, CINAHL, Embase, and the Cochrane library between 2007 and 2017, 12 articles met the inclusion criteria. The majority of the included studies supported the relationship between depression and bone loss in postmenopausal women, although little information is offered as to why this relationship exists. This review summarizes the research that has been completed on depression and bone loss in postmenopausal women and identifies gaps in the literature. These findings will aid in the planning of future research and the development of health care recommendations.
\end{abstract}

Keywords: osteoporosis, depression, osteopenia, vitamin D, parathyroid, physical activity

\section{Introduction}

Osteoporosis and depression are both major causes of disability, morbidity, and mortality throughout the world. Osteoporosis is a disease of low bone mineral density (BMD), or excessive bone loss, affecting 200 million women worldwide. ${ }^{1}$ Osteoporosis disproportionately affects postmenopausal women, with nearly 1 in 2 women over the age of 50 likely to experience an osteoporosis related fracture. ${ }^{2}$ In women over 45 , osteoporosis accounts for more days of hospitalization than diabetes, myocardial infarction, or breast cancer. ${ }^{3}$ Depression, which more commonly affects women throughout the life span, has been linked to reduced BMD. ${ }^{4-8}$ Postmenopausal women have an even greater risk of depression and during this same life stage risk losing a significant amount of bone mass., ${ }^{4}$

There have been several studies that draw a relationship between bone loss and depression, including multiple systematic reviews and meta-analyses. ${ }^{5-8}$ Although depressive symptoms and bone loss are connected, the reason for this relationship has not been identified. As illustrated in Figure 1, the main theories for this connection include etiologies that are: 1) physiological; 2) behavioral; and/or 3 ) medical. ${ }^{9}$ An example of a physiological theory is that depression activates the hypothalamic-pituitary axis with effects such as increased levels of cortisol that have known deleterious effects on bone. An example of a behavioral theory of this connection is that depression 


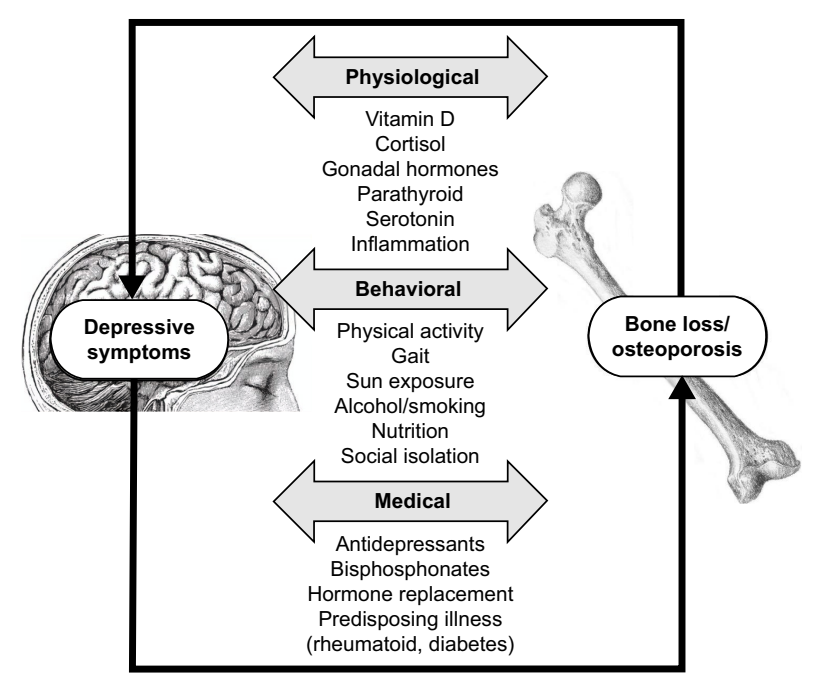

Figure I Some of the proposed variables in the relationship between depressive symptom and bone loss.

reduces physical activity level, thus decreasing bone mass. An example of a medical theory on the link between these variables is that certain medications or illnesses such as rheumatoid arthritis may have relationships to both osteoporosis and depressive symptoms. In addition to these theories are several covariates and potential mediators that could explain the relationship such as low vitamin $\mathrm{D}$, which is related to both depression and osteoporosis. ${ }^{10}$ A relationship has been established between bone fracture and depression, falls and depression, and bone loss and antidepressant use. ${ }^{11-13}$ Each of these connections has different proposed mechanisms, but for the purposes of concision will not be included in this review.

Although there is an established relationship between bone loss and depression, few studies have focused on postmenopausal women. The purposes of this integrative review were to synthesize and summarize the available literature on: 1) the associations between bone loss and depression in postmenopausal women; and 2) potential variables that impact the associations between bone loss and depression in postmenopausal women. Integrative reviews provide a summative picture of a phenomenon by synthesizing the available literature and have the benefit of including studies that use a variety of measuring instruments and varying methodologies. ${ }^{14}$ By conducting this review, we summarize the research that has been completed on depression and bone loss in postmenopausal women as well as identify gaps in the literature. These findings will aid in the planning of future research and the development of health care recommendations.

\section{Bone in postmenopausal women}

Bone remodeling is a coordinated process between bone resorbing osteoclasts and bone forming osteoblasts to maintain skeleton homeostasis and healthy bone mass. ${ }^{15}$ Osteoblasts and osteoclasts are regulated by many factors, including various hormones, nutrients, and physical activity. Menopause and the loss of estrogen are associated with rapid bone loss. Estrogen is integral to maintaining the osteoblast/ osteoclast balance in women. Without a balance between osteoblasts and osteoclasts, osteoclasts resorb bone at a rate faster than the body can replenish bone leading to conditions such as osteopenia (reduced bone mass) and osteoporosis (severe bone mass reduction leading to brittle bones and increased risk of fracture). While estrogen is a critical element in bone turnover, additional factors that are known to affect bone are often present in postmenopausal women including vitamin D deficiency, increased levels of parathyroid hormone (PTH) secretion, and changes in physical activity and skeletal loading. ${ }^{16-18}$ Current first-line treatments for bone loss are lifestyle changes including physical activity, dietary changes, appropriate vitamin D and calcium supplementation, and pharmaceutical bisphosphonates that increase bone mass through suppression of osteoclasts. ${ }^{19}$

Most studies that are available on depression and bone loss are not focused on postmenopausal women, even though postmenopausal women have depression prevalence rates as high as $25 \%{ }^{20}$ and are the most likely population to experience bone loss. ${ }^{21}$ As discussed, estrogen is a critical variable to bone homeostasis, but is also a critical variable in mood and depressive symptoms. Menopausal women have an increased likelihood of reporting depressive symptoms during this life phase. ${ }^{11}$ Taking these factors into consideration, we would expect that the bone loss-depression connection would be more pronounced since the two conditions tend to have high prevalence rates in postmenopausal women. Alternatively, the osteoporosis-depression connection could be less pronounced in postmenopausal women since the covariate of sex hormone depletion has been introduced, perhaps blunting the actual, yet to be determined, linking variable between depression and bone loss.

\section{Previous reviews}

To the authors' knowledge, there are no previous reviews on depression and bone loss in postmenopausal women. There are three major meta-analyses on depression and bone loss. Wu et $\mathrm{al}^{6}$ conducted a meta-analysis with 14 studies and found that depression was associated with decreased BMD at the lumbar spine and hip $\left(-0.053 \mathrm{~g} / \mathrm{cm}^{2}, p=0.003\right.$; 
and $\left.-0.052 \mathrm{~g} / \mathrm{cm}^{2}, p=0.001\right)$. In Yirmiya and Bab's meta-analysis of 23 studies, there was a relationship between bone loss and depression, yet there was only a small effect size ( $d=$ standardized mean difference) for this relationship $(d=-0.23, p<0.001)$. When reanalyzed by sex, the effect size was larger in women than in men ( $d=-0.24$ vs $d=-0.12$ ), and even larger among premenopausal women than in postmenopausal women $(d=-0.31$ vs $d=-0.12)$. Cizza et $\mathrm{al}^{7}$ analyzed 33 articles and found that in individuals with depressive symptoms there was a $4.73 \%$ reduction of BMD at the spine ( $p<0.0001, \mathrm{n}=16$ studies), a $3.53 \%$ reduction of BMD at total femur ( $p<0.001, \mathrm{n}=13$ studies), and a $7.32 \%$ reduction of BMD at femoral neck ( $p<0.0005, \mathrm{n}=8$ studies). Although their sample included both males and females, they found that the reduction at the spine was only significant in females. There appears to be a definitive connection between bone loss and depressive symptoms, although this link has not been explored in a literature review focused exclusively on postmenopausal women.

\section{Materials and methods}

\section{Search methods}

The databases MEDLINE for PubMed, CINAHL, Embase, and the Cochrane library were searched by two abstractors with the search terms "“bone loss' AND 'depression' AND 'postmenopausal women", as well as “"osteoporosis' AND 'depression' AND 'postmenopausal women'”, and “'osteopenia' AND 'depression' AND 'postmenopausal women"'. Results were limited to articles published in the previous 10 years of literature (2007-2017) to include the most up-to-date resources and to focus on studies that have been conducted since the previously mentioned metaanalyses. Additionally, we handsearched the reference lists from the selected citations to ensure inclusion of appropriate articles. The article selection process we used is outlined in Figure 2. Inclusion criteria for articles were: English language, postmenopausal women as the population of study, osteoporosis or BMD as variables of study, and depression or depressive symptoms as variables of study. Exclusion criteria included articles solely about antidepressants and bone loss, depression and falls, articles where the majority of the population was taking an antidepressant medication, and articles with data solely on depression and fractures without information on osteoporosis or BMD. To appraise the quality of the studies to be included, we used four prompts for informing judgments about quality ${ }^{22}: 1$ ) Are the aims and objectives of the research clearly stated? 2) Is the research design clearly specified and appropriate for the aims and

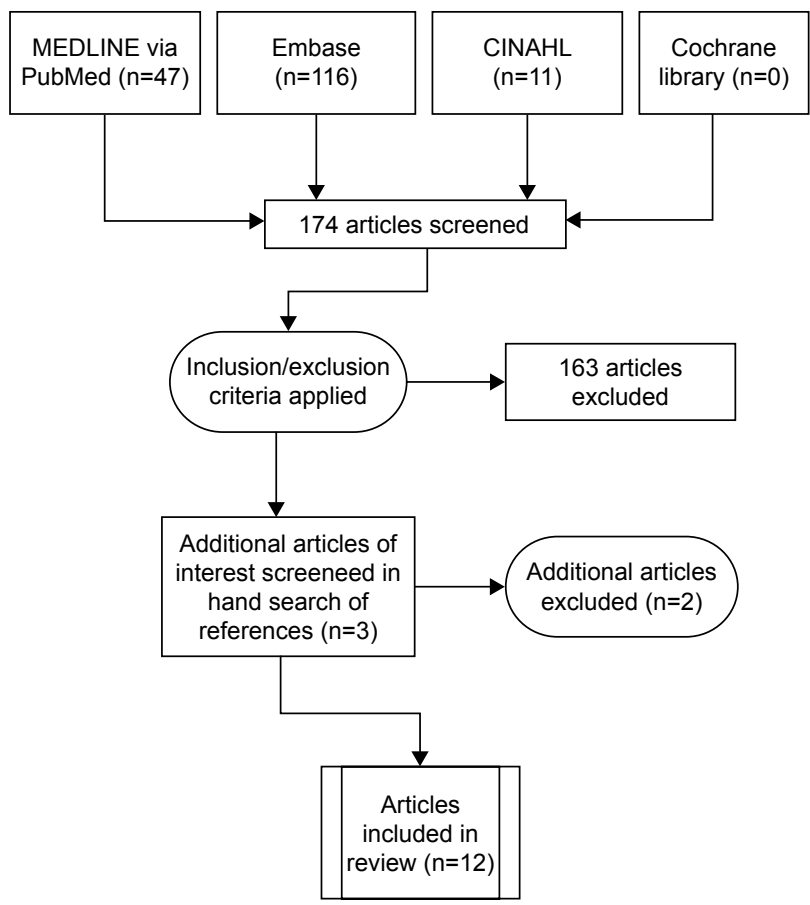

Figure 2 Selection of articles for inclusion in the literature review.

objectives of the research? 3) Do the researchers provide a clear account of the process by which their findings we reproduced? 4) Do the researchers display enough data to support their interpretations and conclusions? 5) Is the method of analysis appropriate and adequately explicated?

\section{Search outcome}

We found 12 articles that met the inclusion criteria for the literature review..$^{23-34}$ The author, year, design, population, measure of bone mass, measure of depression, country of study, and whether a relationship between depression and bone was confirmed in the study are outlined in Table 1.

\section{Characteristics of included studies Geography}

The geographical locations of the included studies were limited including 5 studies were from Asia, 4 studies were from Europe, and 3 studies from the United States.

\section{Measure of depressive symptoms}

The majority of the studies in this review used a screening tool to measure depressive symptoms. A screening tool indicates if a subject has experienced depressive symptoms, whereas the gold standard for measuring depression is a health care provider's diagnosis of Major Depressive Disorder (MDD). Atteritano et $\mathrm{l}^{28}$ used a health care provider's diagnosis as inclusion criteria and found an association between MDD 
Table I Characteristics of included studies

\begin{tabular}{|c|c|c|c|c|c|}
\hline Study & Study design & $\begin{array}{l}\text { Measure of } \\
\text { bone mass }\end{array}$ & $\begin{array}{l}\text { Measure of } \\
\text { depression }\end{array}$ & Country & $\begin{array}{l}\text { Depressive symptoms and } \\
\text { bone loss relationship? }\end{array}$ \\
\hline Bener et $\mathrm{al}^{23} 2016$ & $\begin{array}{l}\text { Cross-sectional analysis, } \\
\text { I,650 PM women }\end{array}$ & DXA & $\mathrm{BDI}$ & Qatar & Yes \\
\hline $\begin{array}{l}\text { Gokosmanoglu et al, }{ }^{24} \\
2016\end{array}$ & $\begin{array}{l}\text { Quasi-experimental, } \\
88 \text { women with PM OP }\end{array}$ & DXA & BDI & Turkey & Yes \\
\hline Seven et al, ${ }^{25} 2016$ & $\begin{array}{l}\text { Cross-sectional, 9I PM } \\
\text { women }\end{array}$ & DXA & $\begin{array}{l}\text { Hamilton Anxiety } \\
\text { and Depression }\end{array}$ & Turkey & No \\
\hline Rauma et $\mathrm{al}^{26} 2014$ & $\begin{array}{l}\text { Cross-sectional }(n=2,167) \\
\text { and longitudinal analysis } \\
(n=I, I 47) \text { of PM women }\end{array}$ & DXA & $\begin{array}{l}\text { LS } 4 \text { item scale, } \\
\text { hospitalization }\end{array}$ & Finland & Yes \\
\hline Xu et al, ${ }^{27} 2014$ & $\begin{array}{l}\text { Cross-sectional, } 100 \text { PM } \\
\text { women }\end{array}$ & DXA & $\begin{array}{l}\text { Hamilton Anxiety } \\
\text { and Depression }\end{array}$ & $\begin{array}{l}\text { People's } \\
\text { Republic of China }\end{array}$ & Yes \\
\hline Atteritano et al, ${ }^{28} 2013$ & $\begin{array}{l}\text { Cross-sectional, } 50 \text { PM } \\
\text { women with MDD and } \\
50 \text { PM matched control }\end{array}$ & $\begin{array}{l}\text { DXA, US } \\
\text { bone }\end{array}$ & $\begin{array}{l}\text { DSM-V by physician } \\
\text { for at least } 2 \text { years }\end{array}$ & Italy & Yes \\
\hline Bistrović et al, 292012 & $\begin{array}{l}\text { Cross-sectional, II } 3 \text { peri- } \\
\text { or PM women }\end{array}$ & DXA & BDI & Croatia & No \\
\hline Erez et al, ${ }^{30} 2012$ & $\begin{array}{l}\text { Cross-sectional, I } 28 \text { PM } \\
\text { women }\end{array}$ & $\mathrm{DXA}$ & $\begin{array}{l}\text { Zung Self-depression } \\
\text { Rating Scale }\end{array}$ & Israel & Yes \\
\hline $\begin{array}{l}\text { Lasaite and } \\
\text { Krasauskiene, }{ }^{31} 2009\end{array}$ & $\begin{array}{l}\text { Cross-sectional, 3I PM } \\
\text { women with OP and } \\
29 \text { matched controls }\end{array}$ & $\begin{array}{l}\text { Self-report } \\
\text { of physician } \\
\text { diagnosis OP }\end{array}$ & $\begin{array}{l}\text { POMS and Hospital } \\
\text { Anxiety and } \\
\text { Depression }\end{array}$ & Lithuania & No \\
\hline Spangler et al, ${ }^{32} 2008$ & $\begin{array}{l}\text { Longitudinal, 6,44I PM } \\
\text { women }\end{array}$ & DXA & $\begin{array}{l}\text { Burnam's scale for } \\
\text { depression }\end{array}$ & USA & Yes \\
\hline Tolea et al,,$^{34} 2007$ & $\begin{array}{l}\text { Cross-sectional, I,350 } \\
\text { Mexican American PM } \\
\text { women }\end{array}$ & $\begin{array}{l}\text { Self-report } \\
\text { of physician } \\
\text { diagnosis OP }\end{array}$ & $\begin{array}{l}\text { Center for } \\
\text { Epidemiologic Studies } \\
\text { Depression Scale }\end{array}$ & USA & Yes \\
\hline Diem et al, ${ }^{33} 2007$ & $\begin{array}{l}\text { Longitudinal analysis, } \\
\text { 3,708 PM women }\end{array}$ & $D X A$ & $\begin{array}{l}\text { Geriatric Depression } \\
\text { Scale }\end{array}$ & USA & Yes \\
\hline
\end{tabular}

Note: Studies included in the literature review on the relationship between depressive symptoms and bone loss in postmenopausal women.

Abbreviations: BDI, Beck Depression Inventory; DSM-V, Diagnostic and Statistical Manual of Mental Disorders, fifth edition; DXA, Dual-energy X-ray absorptiometry; LS, life satisfaction; MDD, Major Depressive Disorder; OP, osteoporosis; PM, postmenopausal; POMS, Profile of Mood States; US, ultrasound.

and decreased BMD. Rauma et $\mathrm{al}^{26}$ examined life satisfaction as their measure of depression as well as subject's report of hospitalization for depression. The remaining studies used depression screening tools. Although not all subjects included in this review had a diagnosis of MDD, all studies included a measure of depressive symptoms.

\section{Measure of bone mass}

All but 2 studies used in this review measured BMD using dual-energy X-ray absorptiometry (DXA). Lasaite and Krasauskiene $^{31}$ and Tolea et $\mathrm{al}^{34}$ included women who had a physician diagnosis of osteoporosis in their sample, yet neither of these studies reported how they measured bone in their control group. Lasaite and Krasauskiene ${ }^{31}$ found no association between a diagnosis of osteoporosis and depressive symptoms in their small sample, whereas Tolea et $\mathrm{al}^{34}$ found a relationship between diagnosis of osteoporosis and depressive symptoms in their large sample. The choice of measure for bone is significant in interpreting the findings.

\section{Results and discussion}

All but one study ${ }^{24}$ in this review had a primary objective to establish a relationship between depressive symptoms and bone loss in a population of postmenopausal women, and 9 of the 12 included studies confirmed this connection.

\section{Studies that found an association between bone loss and depression}

Diem et $\mathrm{al}^{33}$ conducted a longitudinal analysis of postmenopausal women in the USA with approximately 4.4 years between DXA scans. In the analysis that excluded antidepressant users, women who were depressed (Geriatric Depression Scale $>6, n=140$ ) experienced greater bone loss at the total hip than nondepressed women (Geriatric Depression Scale $<6, \mathrm{n}=3,568)(-1.07 \% / \mathrm{yr}$ vs $-0.69 \% / \mathrm{yr} ; p<0.001)$.

Erez et al ${ }^{30}$ studied 128 postmenopausal women in Israel. Women completed the Zung Depression Rating Scale and a DXA and were divided into 3 groups for statistical analysis: osteoporosis $(n=33)$, osteopenia $(n=61)$, and normal BMD 
$(n=34)$. Only 3 women in their sample reported antidepressant use ( 1 with osteoporosis and 2 with normal BMD). The researchers found a negative correlation between depression and BMD at the left hip (depression effect size on BMD left hip $\beta=-0.30 ; p<0.05$; effect size of depression on left hip $\mathrm{T}$ score $\beta=-0.23 ; p<0.05$ ); and right hip (effect size of depression on BMD in units and T score left hip $\beta=-0.28$; $p<0.05$ ). There was no significant relationship between depression and BMD at the spine.

$\mathrm{Xu}$ et $\mathrm{a}^{27}$ studied 100 postmenopausal women in China. Women completed the Hamilton Anxiety and Depression Scale and underwent lumbar and hip DXA. They found significant differences in the lumbar and hip BMD between the mild depression group $(n=36)$ and control group $(n=50)$ and between severe depression group $(n=14)$ and control group ( $p<0.05)$. Overall depression scores were negatively related to lumbar BMD $(\gamma=-0.591 ; p<0.05)$, and hip BMD $(\gamma=-0.474 ; p<0.05)$.

Rauma et $\mathrm{al}^{26}$ conducted a longitudinal analysis that included 1,147 women out of an original sample of 2,167 postmenopausal women from Finland who underwent femoral neck DXA scan and a life satisfaction screening 10 years apart. The 4-item life satisfaction scale that was used has been correlated with the Beck depression inventory (BDI). ${ }^{35}$ The authors also included participant hospitalization for depression as an indicator of depression, although this number was low $(n=11)$, it was shown to reduce BMD by $0.5 \%$ annually. In the baseline analysis, $9.7 \%$ of the population was using antidepressants, although the authors found no significant correlation between antidepressant use and BMD. The authors found that women who had improved life satisfaction scores over the 10 years had the least amount of bone loss $(-0.28 \%$ BMD femur annual loss) compared to those whose life satisfaction deteriorated $(-0.53 \%$ BMD femur annual loss).

Bener et $\mathrm{al}^{23}$ studied 607 Arab postmenopausal women in Qatar. Women were excluded if they were using antidepressants. Women were administered the BDI and DXA at the lumbar spine, and right and left femur. The authors found that postmenopausal women with depression $(n=144)$ were likely to have a higher rate of bone loss and osteoporosis than nondepressed postmenopausal women. Women who were depressed and had a diagnosis of osteoporosis had reduced $\mathrm{T}$ scores and $\mathrm{Z}$ scores $(-2.615,-0.015, p<0.001)$ compared to women with osteoporosis without depression $(-1.835$, $0.07, p<0.001)$. Women with osteopenia and depression had reduced $\mathrm{T}$ scores and $\mathrm{Z}$ scores $(-2.475,-0.12, p<0.001)$ compared to women with osteopenia who did not have depression $(-1.646,0.05, p<0.001)$.
Atteritano et $\mathrm{al}^{28}$ studied 50 postmenopausal Italian women with MDD who were not on antidepressants and 50 controls who were postmenopausal women without MDD matched for age, body mass index, menopausal age, and smoking habits. Women with MDD had significantly reduced BMD compared to women without MDD in all measured areas (eg, femoral BMD $\left(\mathrm{g} / \mathrm{cm}^{2}\right) 0.71$ vs $0.58, p<0.001)$.

Spangler et $\mathrm{al}^{32}$ found no difference between measures at baseline and 3 year BMD between depressed and nondepressed postmenopausal women (as measured by the Burnam's scale for depression) in their larger sample $(n=6,441)$. When the sample was analyzed excluding women on antidepressants, there was a statistically significant difference in whole-body BMD associated with depressive symptoms $\left(-0.0036 \mathrm{~g} / \mathrm{cm}^{2} ; p=0.05\right)$. No differences were reported between depressed and nondepressed women for BMD at the hip or spine. Limitations in this study included that depression was only measured at baseline, and that the number of depressed women not taking antidepressants was a small subset of the population $(n=369)$.

Tolea et $\mathrm{al}^{34}$ studied 1,350 Mexican American community dwelling postmenopausal women and analyzed 7 years of prospective data on depressive symptoms using the Center for Epidemiological Studies Depression Scale and selfreported diagnosis of osteoporosis. Of this sample, 7.8\% of the sample was on antidepressants. ${ }^{34}$ The researchers found that depressive symptomatology was predictive for self-reported osteoporosis (odds ratio: 1.42; 95\% CI: 1.05, 1.92) and when controlled for other significant predictors (odds ratio: 1.39; 95\% CI: 1.02, 1.91). ${ }^{34}$

\section{Changes to depression scores through bisphosphonate}

Gokosmanoglu et al's ${ }^{24}$ study had a different design than the rest of the included studies. Women in their study were given an intervention of once yearly bisphosphonate (zoledronic acid). Changes in BMD and depression as measured by the BDI were examined 12 months after the intervention. The sample included 88 postmenopausal women in Turkey without psychiatric disease, and with no reported use of antidepressants. Bisphosphonates are known to improve BMD, which they did in this study, but no other studies to our knowledge have studied the effects of bisphosphonate use on depression or quality of life scores. The BDI, where higher scores correlate with greater depressive symptoms, were reduced at the same time BMD improved (BDI: $16.51-13.42, p=0.001$ ). 


\section{Studies that did not find an association between bone loss and depression}

There were 3 studies that found no association between depressive symptoms and bone loss in their sample of postmenopausal women. ${ }^{25,29,31}$ Bistrović et $\mathrm{al}^{29}$ study was the only sample to include both perimenopausal and postmenopausal women, and women with a diagnosis of depression prior to the study were excluded. These study criteria may have affected the association between depression and bone loss. In Seven et al's ${ }^{25}$ study of 91 postmenopausal women, there was no significant association between depressive symptoms through the Hamilton Anxiety and Depression Scale and BMD. The majority of Seven et al's ${ }^{25}$ sample were osteopenic or normal instead of osteoporotic, and this may also have affected the results of the study.

\section{Variables related to bone loss and depression}

As previously discussed, and outlined in Figure 1, there are multiple variables to consider in the relationship between depression and bone loss. These variables fall within the overarching theories that are 1) physiological, 2) behavioral, or 3) medical. In this literature review, there were relatively few variables of consideration in the depression bone loss connection. Physiological variables in the included studies were vitamin $\mathrm{D},{ }^{23,24,28}$ hormonal levels, ${ }^{25,27} \mathrm{PTH},{ }^{24,28}$ and cortisol. ${ }^{28}$ The only behavioral variable included was physical activity, and the only included medical variable was bisphosphonates.

\section{Physiological Vitamin D}

Vitamin D is a fat-soluble vitamin synthesized through sun exposure that is critical to bone absorption of calcium and necessary for healthy bone. Women with osteoporosis or osteopenia are known to have low vitamin D levels. ${ }^{36}$ Vitamin D depletion has been linked to depression and has been proposed as a potential reason individuals experience Seasonal Affective Disorder. ${ }^{37,38}$ Seasonal Affective Disorder includes depressive symptoms more common in the winter months when individuals are less likely to venture outdoors. Depressive symptoms at any time of the year may reduce sun exposure, and modern lifestyle puts most individuals at risk for low vitamin D. Conversely, the vitamin D depression connection may have little to do with the sun and be related to another mediating factor. Nevertheless, low vitamin $\mathrm{D}$ levels are associated with both bone loss and depression. In Bener et al's ${ }^{23}$ analysis, women were divided into depressed vs nondepressed groups and it was found that depressed women had both lower BMD and lower vitamin D. Atteritano et $\mathrm{al}^{28}$ found that women with MDD had significantly lower vitamin D levels and lower BMD, but did not measure relationships between vitamin $\mathrm{d}$ and depression. Gokosmanoglu et $\mathrm{al}^{24}$ found that 12 months after administration of a bisphosphonate, both depressive symptoms and vitamin D were improved. These researchers also did not examine relationships between vitamin $\mathrm{D}$ and depression.

\section{Gonadal hormones}

In postmenopausal women, the natural declines of sex hormones, most specifically estrogen, have significant effects on both physiological and psychological systems. While many other sex hormones have an effect on bone, the loss of estrogen is thought to be one of the most significant factors. ${ }^{39}$ Estrogen regulates bone turnover partially through its inhibition of osteoclasts. ${ }^{36}$ Estrogen has also been associated with depression in women throughout the life span and has been indicated as related to premenstrual dysphoric disorder, postpartum depression, and postmenopausal depression. ${ }^{40}$ During menopause, a woman experiences a more definitive loss of estrogen, and during this time her likelihood of having depressive symptoms increases. $\mathrm{Xu}$ et $\mathrm{al}^{27}$ found that women with low BMD had higher depressive symptoms (both mild and severe depression) and had significantly lower estrogen compared to women with healthy BMD. Seven et al, ${ }^{25}$ who found no relationship between BMD and depressive symptoms, also studied hormonal variables but found no differences in BMD results according to levels of estrogen, dehydroepiandrosterone (DHEA), follicle stimulating hormone, and luteinizing hormone for either BMD or depressive symptoms.

\section{Parathyroid hormone}

PTH regulates calcium in the body by removing calcium from bones. Elevated levels of PTH and hyperparathyroidism are known causes of osteoporosis. ${ }^{41}$ PTH has also been related to depression and decreased quality of life. In patients in whom the parathyroid glands have been removed, there is evidence that psychological symptoms such as depression have been reduced. ${ }^{42}$ In this review, PTH was only measured in 2 studies. Atteritanto et $\mathrm{al}^{28}$ found that depressed women with low BMD had increased PTH. The researchers concluded that depression is a risk factor for bone loss, and they theorized that depression contributes to osteoporosis pathogenesis through PTH. Gokosmanoglu et $\mathrm{al}^{24}$ found that after bisphosphonate administration, PTH decreased 
(as would be expected) and that BMD increased and depressive symptoms decreased.

\section{Cortisol}

Cortisol is produced by the adrenal glands and is known to have a negative effect on BMD by increasing bone resorption and decreasing bone formation. Hypercortisolism and the use of glucocorticoid drugs are indicated in osteoporosis pathogenesis. ${ }^{43}$ Cortisol is secreted by the body in response to stress and is associated with depression. Depressed individuals have higher peaking cortisol levels that do not level off appropriately throughout the day. ${ }^{44}$ In this circumstance, the directionality of the relationship between cortisol and depression has not been determined. Only one study in our review studied cortisol as a variable. ${ }^{28}$ This study did not find a significant difference between urinary cortisol levels between depressed and nondepressed women. The authors therefore ruled cortisol out as a potential mediator between the relationship they discovered between BMD and depressive symptoms. ${ }^{28}$

\section{Behavioral}

\section{Physical activity}

Physical activity is known to improve both depressive symptoms and BMD. ${ }^{45,46}$ Atteritanto et $\mathrm{al}^{28}$ found no differences between reported physical activity and depressive symptoms or BMD. Rauma et $\mathrm{al}^{26}$ used grip strength as a measure of physical activity and found that decreased grip strength was associated with decreased life satisfaction and decreased BMD. When adjusting for grip strength, the relationship between life satisfaction and BMD weakened, highlighting that a potential connective variable between depressive symptoms and BMD may be physical activity.

\section{Medical}

\section{Bisphosphonates}

Bisphosphonates are a first-line pharmacological treatment for osteoporosis in postmenopausal women. Bisphosphonates are believed to work by inhibiting the resorption of bone and by allowing for proliferation of new bone. ${ }^{47}$ Gokosmanoglu et $\mathrm{al}^{24}$ found that the administration of a once yearly bisphosphonate (zoledronic acid) increased BMD and decreased depressive symptoms at a 12-month follow-up. The authors did not attempt to find an association between these variables in this quasi-experimental designed study. There is currently no research linking bisphosphonates to reduced depressive symptoms; however, it is expected that BP will increase BMD. Rauma et $\mathrm{al}^{26}$ found that women with increased life satisfaction were more likely to have higher BMD, and that women taking bisphosphonates were more likely to report increased life satisfaction.

\section{Recommendations}

Although several physiological, behavioral, and medical processes have been theorized in the relationship between bone loss and depression, very few have been examined in the literature. The majority of the studies included in this review supported a relationship between bone loss and depressive symptoms in postmenopausal women. Nearly all studies were observational. The only study that was experimental did not include a control group. ${ }^{24}$ Many studies were pilot or small sample studies with the simple goal of establishing a relationship between bone loss and depressive symptoms in postmenopausal women. Other variables that were mentioned in the included studies were, in general, not studied in the context of the bone loss-depression relationship. Previous reviews and meta-analysis have confirmed there is an association between depressive symptoms and bone loss; however, further research is needed in larger samples to solidify this relationship in postmenopausal women and to examine why the relationship exists. ${ }^{5-7}$

\section{Recommendations for future research}

There were several variables accounted for in the articles included in this review, but very few of these variables were examined within the depression bone loss relationship. Vitamin D and physical activity are of particular interest since they each have known associations to both depression and bone loss in postmenopausal women. Study of physical activity, as a covariate, should include objective measures including the use of wearable activity monitoring devices. PTH involvement in the bone loss-depression relationship is an area that needs further consideration and study.

The finding that a bisphosphonate may be related to an improvement in depressive symptoms is novel. In regard to the proposed bidirectional relationship between bone loss and depressive symptoms, the improvement in depression related to administration of a drug that targets bone lends itself toward the theory that bone loss may cause depressive symptoms. If further studies confirm that bisphosphonates decrease depressive symptoms, the theory that bone signaling may have a causative effect for depressive symptoms instead of depressive symptoms having an effect on bone should be considered further. How improving bone through the use of bisphosphonates or other interventions can improve mood and cognitive variables is an area in need of study. 
Although several countries were included in this study, the majority of the countries in the world were not represented. Although multiple races and ethnicities were represented, further studies on the differences between race, ethnicity, and geographic location in the depression bone loss relationship are needed.

Overall, the amount of research available on this topic is limited. Due to the discovery that antidepressants reduce bone mass, the research has shifted away from the depressive symptoms and bone loss connection, especially in postmenopausal women who experience these co-occurring conditions more than any other population. Further research is needed with large samples sizes with prospective designs to solidify these relationships.

\section{Recommendations for clinical practice}

Osteoporosis and osteopenia are often considered silent diseases with no symptoms until a woman experiences a fracture. The findings in this review suggest that depressive symptoms are indicative of bone loss. Clinicians evaluating their postmenopausal patients for bone loss should consider depressive symptoms in their patients as a potential risk identifier for osteopenia or osteoporosis, and then investigate, diagnose, and treat as indicated.

\section{Conclusion}

Emerging evidence indicates that bone loss is connected to depressive symptoms in postmenopausal women. Further research is needed to solidify this connection, and additional covariates and mediators need to be explored. Bisphosphonates as a treatment for both depressive symptoms and improvement of bone deserves further study in larger groups. Vitamin D, physical activity, and PTH, which are well studied in bone loss, should be examined through a lens that includes their association to depressive symptoms. Although the link between depressive symptoms and bone loss in postmenopausal women has not been determined, clinicians should consider depressive symptoms in a postmenopausal woman as an indicator for further exploration of her bone health.

\section{Disclosure}

The authors report no conflicts of interest in this work.

\section{References}

1. Kanis JA. Assessment of Osteoporosis at the Primary Health-Care Level. Technical Report. WHO Collaborating Centre, University of Sheffield, UK: World Health Organization; 2008.

2. US Preventive Services Task Force. Screening for osteoporosis: US preventive services task force recommendation statement. Ann Int Med. 2011;154(5):356.
3. Singer A, Exuzides A, Spangler L, et al. Burden of illness for osteoporotic fractures compared with other serious diseases among postmenopausal women in the United States. Mayo Clin Proc. 2015;90(1):53-62.

4. Weber MT, Maki PM, McDermott MP. Cognition and mood in perimenopause: a systematic review and meta-analysis. J Steroid Biochem Mol Biol. 2014;142:90-98.

5. Yirmiya R, Bab I. Major depression is a risk factor for low bone mineral density: a meta-analysis. Biol Psychiatry. 2009;66(5):423-432.

6. Wu Q, Magnus JH, Liu J, Bencaz AF, Hentz JG. Depression and low bone mineral density: a meta-analysis of epidemiologic studies. Osteoporos Int. 2009;20(8):1309-1320.

7. Cizza G, Primma S, Coyle M, Gourgiotis L, Csako G. Depression and osteoporosis: a research synthesis with meta-analysis. Horm Metab Res. 2010;42(7):467-482.

8. Cizza G, Primma S, Csako G. Depression as a risk factor for osteoporosis. Trends Endocrinol Metab. 2009;20(8):367-373.

9. Mezuk B, Eaton WW, Golden SH. Depression and osteoporosis: epidemiology and potential mediating pathways. Osteoporos Int. 2008;19(1):1-12.

10. Anglin RE, Samaan Z, Walter SD, McDonald SD. Vitamin D deficiency and depression in adults: systematic review and meta-analysis. $\mathrm{Br} J$ Psychiatry. 2013;202:100-107.

11. Wu Q, Liu J, Gallegos-Orozco JF, Hentz JG. Depression, fracture risk, and bone loss: a meta-analysis of cohort studies. Osteoporos Int. 2010;21(10):1627-1635.

12. Kvelde T, McVeigh C, Toson B, et al. Depressive symptomatology as a risk factor for falls in older people: systematic review and meta-analysis. J Am Geriatr Soc. 2013;61(5):694-706.

13. Wu Q, Bencaz AF, Hentz JG, Crowell MD. Selective serotonin reuptake inhibitor treatment and risk of fractures: a meta-analysis of cohort and case-control studies. Osteoporos Int. 2012;23(1):365-375.

14. Whittemore R, Knafl K. The integrative review: updated methodology. $J$ Adv Nurs. 2005;52(5):546-553.

15. Manolagas SC. Birth and death of bone cells: basic regulatory mechanisms and implications for the pathogenesis and treatment of osteoporosis. Endocr Rev. 2000;21(2):115-137.

16. Gallagher JC. Vitamin D and aging. Endocrinol Metab Clin North Am. 2013;42(2):319-332.

17. Carrivick SJ, Walsh JP, Brown SJ, Wardrop R, Hadlow NC. Brief report: does PTH increase with age, independent of 25-hydroxyvitamin D, phosphate, renal function, and ionized calcium? J Clin Endocrinol Metab. 2015;100(5):2131-2134.

18. Zhao R, Xu Z, Zhao M. Effects of oestrogen treatment on skeletal response to exercise in the hips and spine in postmenopausal women: a meta-analysis. Sports Med. 2015;45(8):1163-1173.

19. Eriksen EF. Treatment of osteopenia. Rev Endocr Metab Disord. 2012;13(3):209-223.

20. Campbell KE, Szoeke CE, Dennerstein L. The course of depressive symptoms during the postmenopause: a review. Women's Midlife Health. 2015;1(1):3.

21. Dawson-Hughes B, El-Hajj Fuleihan G, Clark P. Bone care for the postmenopausal woman. Nyon, Switzerland: International Osteoporosis Foundation; 2013.

22. Dixon-Woods M, Cavers D, Agarwal S, et al. Conducting a critical interpretive synthesis of the literature on access to healthcare by vulnerable groups. BMC Med Res Methodol. 2006;6:35.

23. Bener A, Saleh NM, Bhugra D. Depressive symptoms and bone mineral density in menopause and postmenopausal women: a still increasing and neglected problem. J Family Med Prim Care. 2016;5(1):143-149.

24. Gokosmanoglu F, Varim C, Atmaca A, Atmaca MH, Colak R. The effects of zoledronic acid treatment on depression and quality of life in women with postmenopausal osteoporosis: a clinical trial study. J Res Med Sci. 2016;21:112.

25. Seven A, Yuksel B, Kabil Kucur S, et al. The evaluation of hormonal and psychological parameters that affect bone mineral density in postmenopausal women. Eur Rev Med Pharmacol Sci. 2016; 20(1):20-25. 
26. Rauma PH, Koivumaa-Honkanen H, Williams LJ, Tuppurainen MT, Kröger HP, Honkanen RJ. Life satisfaction and bone mineral density among postmenopausal women: cross-sectional and longitudinal associations. Psychosom Med. 2014;76(9):709-715.

27. Xu C, Hu J, Han Y, Hu M, Zhou X, Tao M. Correlation between bone mineral density and depression in postmenopausal women. Acta Med Mediterr. 2014;30(6):1397-1401.

28. Atteritano M, Lasco A, Mazzaferro S, et al. Bone mineral density, quantitative ultrasound parameters and bone metabolism in postmenopausal women with depression. Intern Emerg Med. 2013;8(6):485-491.

29. Bistrović IL, Roncević-Grzeta I, Crncević-Orlić Z, et al. Connection of depression and bone loss in perimenopausal and postmenopausal women. Coll Antropol. 2012;36(4):1219-1223.

30. Erez HB, Weller A, Vaisman N, Kreitler S. The relationship of depression, anxiety and stress with low bone mineral density in postmenopausal women. Arch Osteoporos. 2012;7:247-255.

31. Lasaite L, Krasauskiene A. Psychological state, quality of life, and body composition in postmenopausal women with osteoporosis in Lithuania Arch Osteoporos. 2009;4(1-2):85-90.

32. Spangler L, Scholes D, Brunner RL, et al. Depressive symptoms, bone loss, and fractures in postmenopausal women. J Gen Intern Med. 2008;23(5):567-574.

33. Diem SJ, Blackwell TL, Stone KL, et al. Depressive symptoms and rates of bone loss at the hip in older women. J Am Geriatr Soc. 2007; 55(6):824-831.

34. Tolea MI, Black SA, Carter-Pokras OD, Kling MA. Depressive symptoms as a risk factor for osteoporosis and fractures in older Mexican American women. Osteoporos Int. 2007;18(3):315-322.

35. Koivumaa-Honkanen H, Kaprio J, Honkanen R, Viinamäki H, Koskenvuo M. Life satisfaction and depression in a 15-year follow-up of healthy adults. Soc Psychiatry Psychiatr Epidemiol. 2004;39(12): 994-999.

36. Manolagas SC, O'Brien CA, Almeida M. The role of estrogen and androgen receptors in bone health and disease. Nat Rev Endocrinol. 2013; 9(12):699-712.
37. Jovanova O, Aarts N, Noordam R, Zillikens MC, Hofman A, Tiemeier H Vitamin D serum levels are cross-sectionally but not prospectively associated with late-life depression. Acta Psychiatr Scand. 2017 135(3):185-194

38. Premkumar M, Sable T, Dhanwal D, Dewan R. Vitamin D homeostasis, bone mineral metabolism, and seasonal affective disorder during 1 year of Antarctic residence. Arch Osteoporos. 2013;8:129.

39. Cauley JA. Estrogen and bone health in men and women. Steroids. 2015;99(Pt A):11-15.

40. Schiller CE, Johnson SL, Abate AC, Schmidt PJ, Rubinow DR. Reproductive Steroid regulation of mood and behavior. Compr Physiol. 2016;6(3):1135-1160

41. Martin TJ. Parathyroid hormone-related protein, its regulation of cartilage and bone development, and role in treating bone diseases. Physiol Rev. 2016;96(3):831-871.

42. Walker MD, Rubin M, Silverberg SJ. Nontraditional manifestations of primary hyperparathyroidism. J Clin Densitom. 2013;16(1):40-47.

43. Seibel MJ, Cooper MS, Zhou H. Glucocorticoid-induced osteoporosis: mechanisms, management, and future perspectives. Lancet Diabetes Endocrinol. 2013;1(1):59-70.

44. Frodl T, O'Keane V. How does the brain deal with cumulative stress? A review with focus on developmental stress, HPA axis function and hippocampal structure in humans. Neurobiol Dis. 2013;52:24-37.

45. Chastin SF, Mandrichenko O, Helbostadt JL, Skelton DA. Associations between objectively-measured sedentary behaviour and physical activity with bone mineral density in adults and older adults, the NHANES study. Bone. 2014;64:254-262.

46. Hallgren M, Herring MP, Owen N, et al. Exercise, Physical activity, and sedentary behavior in the treatment of depression: broadening the scientific perspectives and clinical opportunities. Front Psychiatry. 2016;7(36):1-5

47. Weaver CM, Alexander DD, Boushey CJ, et al. Calcium plus vitamin D supplementation and risk of fractures: an updated meta-analysis from the National Osteoporosis Foundation. Osteoporos Int. 2016 27(1):367-376.
International Journal of Women's Health

\section{Publish your work in this journal}

The International Journal of Women's Health is an international, peerreviewed open-access journal publishing original research, reports, editorials, reviews and commentaries on all aspects of women's healthcare including gynecology, obstetrics, and breast cancer. The manuscript management system is completely online and includes

\section{Dovepress}

a very quick and fair peer-review system, which is all easy to use. Visit http://www.dovepress.com/testimonials.php to read real quotes from published authors. 